Article

\title{
Kinetic Studies that Evaluate the Solvolytic Mechanisms of Allyl and Vinyl Chloroformate Esters
}

Malcolm J. D'Souza ${ }^{1, *}$, Aaron F. Givens ${ }^{1, \dagger}$, Peter A. Lorchak ${ }^{1, \dagger}$, Abigail E. Greenwood ${ }^{1, \dagger}$, Stacey L. Gottschall ${ }^{1, \dagger}$, Shannon E. Carter ${ }^{1, \dagger}$ and Dennis N. Kevill ${ }^{2, *}$

1 Department of Chemistry, Wesley College, 120 N. State Street, Dover, DE 19901-3875, USA

2 Department of Chemistry and Biochemistry, Northern Illinois University, DeKalb, IL 60115-2862, USA

$\dagger$ These authors contributed equally to this work.

* Authors to whom correspondence should be addressed; E-Mails: dsouzama@wesley.edu (M.J.D.); dkevill@niu.edu (D.N.K.); Tel.: +1-302-736-2528 (M.J.D.); +1-815-753-6882 (D.N.K.); Fax: +1-302-736-2301 (M.J.D.); +1-815-753-4802 (D.N.K.).

Received: 16 February 2013; in revised form: 26 March 2013 / Accepted: 28 March 2013 / Published: 2 April 2013

\begin{abstract}
At $25.0{ }^{\circ} \mathrm{C}$ the specific rates of solvolysis for allyl and vinyl chloroformates have been determined in a wide mix of pure and aqueous organic mixtures. In all the solvents studied, vinyl chloroformate was found to react significantly faster than allyl chloroformate. Multiple correlation analyses of these rates are completed using the extended (two-term) Grunwald-Winstein equation with incorporation of literature values for solvent nucleophilicity $\left(N_{\mathrm{T}}\right)$ and solvent ionizing power $\left(Y_{\mathrm{Cl}}\right)$. Both substrates were found to solvolyze by similar dual bimolecular carbonyl-addition and unimolecular ionization channels, each heavily dependent upon the solvents nucleophilicity and ionizing ability.
\end{abstract}

Keywords: allyl chloroformate; vinyl chloroformate; mechanisms; solvolysis; nucleophilicity; ionizing power; $\pi$ electron cloud; Grunwald-Winstein equation; Linear Free Energy Relationships (LFERs) 


\section{Introduction}

Profound interest in the use of choroformate esters began during World War I due to their ability to cause immense physiological damage [1-3]. Beginning in the 1940s interest in more advantageous agricultural applications commenced with the use of chloroformate esters in a number of herbicide, fungicide, and insecticide formulations [4]. During the past seventy years, both saturated and unsaturated chloroformate esters have gained greater importance commercially due to their many applications as protecting groups and as precursors in the synthesis of novel prodrugs [5-7].

Quantitative linear free energy relationships (LFERs) such as the simple and extended Grunwald-Winstein [Equations (1) and (2)] [8] have been successfully employed [9,10] to elucidate the varying solvolytic mechanism of reaction of such chloroformate esters in a variety of hydroxylic solvents with widely varying nucleophilic and ionizing abilities.

In Equations (1) and (2), $k$ is the specific rate of solvolysis of a chloroformate ester in a given solvent and $k_{o}$ is the specific rate of that same substrate in $80 \%$ ethanol (taken as the standard solvent), $m$ represents the sensitivity to changes in the solvent ionizing power $Y_{\mathrm{X}}$ (based on the solvolysis of 1- or 2-adamantyl derivatives) [11-16], $c$ is a constant (residual) term, and $l$ is the sensitivity to changes in solvent nucleophilicity $N_{\mathrm{T}}$ (determined from the rates obtained for the solvolysis of the $S$-methyldibenzothiophenium ion) [17,18].

$$
\begin{gathered}
\log \left(k / k_{o}\right)=m Y_{\mathrm{X}}+c \\
\log \left(k / k_{o}\right)=l N_{\mathrm{T}}+m Y_{\mathrm{X}}+c
\end{gathered}
$$

Solvolytic data for a variety of substituted phenyl chloroformates have been documented and thorough Grunwald-Winstein (G-W) analyses of the available experimental results using Equation (2) have been published [9,10,19-31]. The kinetic solvent isotope effects (KSIEs) in methanol and methanol-d $\left(k_{\mathrm{MeOH}} / k_{\mathrm{MeOD}}\right)$ for the substituted phenyl chloroformates indicate that general-base catalysis is operating, and its importance decreases with an increase in electron-donating ability of the substituent $[21,26,30,32,33]$. For the parent phenyl chloroformate (1), over a full-range of 49 pure and binary solvents of widely varying nucleophilicity and ionizing power values, the G-W [Equation (2)] analyses resulted in an $l$ value of 1.66 and an $m$ value of 0.56 [27]. It was suggested [10,23,27,30,31] that such $l$ (bond making) and $m$ (bond breaking) values be taken as typical values that are to be expected for substrates that proceed with a rate-determining addition step in a stepwise carbonyl addition-elimination process. Other research groups also proposed homogenous stepwise mechanisms for $\mathbf{1}$, where the formation of a zwitterionic tetrahedral intermediate is the rate-determining step [34-38]. Like 1, recent G-W analyses for the solvolysis of 1- and 2-naphthyl chloroformates also show that the bimolecular addition-elimination pathway is robust in a wide variety of solvents [39].

For primary alkyl chloroformates the rate-determining carbonyl-addition process is the dominant mechanism in a majority of the solvents studied, and in the fluoroalcohols (solvents with low nuclophilicity and high ionizing ability), an ionization mechanism with strong nucleophilic solvation of the developing acylium ion is favored [40-45]. The strongest initial evidence for such a rate-determining addition-elimination process came from a study that compared the experimental rates obtained for $n$-octyl chloroformate and $n$-octyl fluoroformate in identical solvents [42] (of widely varying nucleophilicity and ionizing power values). The comparison showed a $\mathrm{F}: \mathrm{Cl}$ rate ratio that was 
greater than unity. This ratio is consistent with the addition step of carbonyl-addition process being rate determining. Multiple studies contrasting other alkyl haloformate esters [46-50] show that the fluoroformates that have a stronger carbon-fluorine bond solvolyze faster than their corresponding chloroformate esters and such a high $\mathrm{F}: \mathrm{Cl}$ ratio also endures in benzoyl halides $[33,51,52]$.

On the other hand for secondary chloroformates, an evaluation of the kinetic rate data obtained for the bulk of the solutions studied resulted in a proposal that isopropyl chloroformate [53] and 2-adamantyl chloroformate [54] show dominant solvolysis-decomposition with loss of the $\mathrm{CO}_{2}$ molecule. This mechanism parallels the behavior observed for tertiary 1-adamantyl chloroformate in all of the solvents studied where the major products are the decomposition product, 1-adamantyl chloride, and an ether and/or the alcohol (depending on the solvent components) [55].

Competing addition-elimination and solvolysis-decomposition patterns were observed for benzyl and $p$-nitrobenzyl chloroformates [56]. The dominance of one pathway over the other was shown to be strongly dependent on the solvent's nucleophilicity value and its ionizing power ability [56].

Isopropenyl chloroformate (2) was the first alkenyl chloroformate to be exhaustively analyzed using Equation (2) in 51 solvents [57]. A bimolecular tetrahedral addition-elimination pathway was the predominant reaction mechanism observed, and a superimposed ionization pathway was shown to make a significant contribution in the four 97\%-70\% 1,1,1,3,3,3-hexafluoro-2-propanol (HFIP) and 97\% 2,2,2-trifluoroethanol (TFE) mixtures with water.

So far the two alkynyl chloroformates to be evaluated using the extended Grunwald-Winstein Equation [Equation (2)] are; propargyl [58] and 2-butyn-1-yl chloroformate [31]. For propargyl chloroformate, the tetrahedral stepwise addition-elimination pathway was confirmed for all 22 solvents studied [58]. 2-butyn-1-yl chloroformate differs from the propargyl substrate by the presence of an adjoining methyl group on the $\beta$-triple bond. For this alkynyl containing compound, the addition-elimination pathway again dominates the spectrum of the solvents considered, but the reaction switches over to an ionization channel in the two most strongly hydrogen-bonding solvents studied, 97\% and 90\% HFIP [31].

The alkenyl chloroformates, allyl (3) and vinyl (4) chloroformates have gained recent media attention due to their meaningful use in surface coating technology to create commercial bacterial-resistant amphiphilic polymers [59]. The solvolyses of allyl chloroformate (3) was recently evaluated in 35 solvents at $35.0^{\circ} \mathrm{C}$ [60]. The authors Koh and Kang proposed a lose bimolecular $\mathrm{S}_{\mathrm{N}} 2$ reaction based on the magnitudes of the Grunwald-Winstein $l$ and $m$ values obtained, the activation parameters and KSIE determinations, and the product selectivity data in alcohol/water mixtures [60]. The rate data reported for the ethanolysis of allyl chloroformate at $25.0{ }^{\circ} \mathrm{C}$ [60] was found to be smaller than the corresponding value obtained for benzyl chloroformate (5) at the same temperature [56].

In general, studies have shown that conjugated allylic substrates show enhanced reactivity due to the proximity of the pi system of the carbon-carbon double bond [29,33,61]. Additionally due to the possibility of increased resonance stabilization in the cation, allyl, benzyl, and benzoyl substrates typically tend to favor stepwise unimolecular $S_{N} 1$ (dissociative) reactions [29,33,51,52,62-65]. An allyl cation with two resonance contributors is shown to have approximately the same stability as a secondary alkyl cation [66]. On the other hand reactivity at an $\mathrm{sp}^{2}$ carbon of vinyl substrates is dependent on whether the substrate is activated or unactivated, for alkyl-substituted vinyl triflates are 
shown to solvolyze through ion-pair mechanisms where nucleophilic solvation is important in substrates where the $\beta$ hydrogen is trans to the leaving group [66-73].

In Figure 1, we present the three-dimensional arrangements of 1-5. The molecular structures drawn clearly show the proximity of the $\pi$-bond to the ether oxygen. This environment could influence the polarization of the bonding to the ether oxygen and as a consequence, this would affect any inductive and/or mesomeric effects observed. To further probe the potential of any accelerating or deshielding $\pi$-conjugation effects, we now present the analysis of our experimental first-order specific rates of solvolysis of allyl (3) and vinyl (4) chloroformates at $25.0^{\circ} \mathrm{C}$. We also reanalyze the Koh and Kang data [60] for 3 at $35.0{ }^{\circ} \mathrm{C}$. We compare the solvolytic data obtained at $25.0{ }^{\circ} \mathrm{C}$ to the available literature values of phenyl (1) [21-23,26,27] and benzyl (5) [56] chloroformate at the same temperature.

Figure 1. Molecular structures of phenyl chloroformate (1), isopropenyl chloroformate (2), allyl chloroformate (3), vinyl chloroformate (4) and benzyl chloroformate (5).

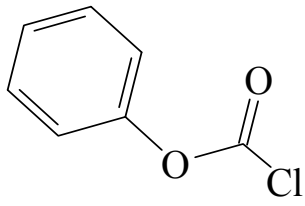

1<smiles>C=C(C)OC(=O)Cl</smiles>

2<smiles>C=CCOC(=O)Cl</smiles>

3

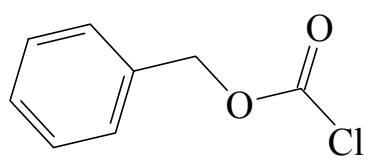

5

\section{Results and Discussion}

The rates of solvolysis for allyl (3) and vinyl (4) chloroformate are measured in 20 and 17 pure and binary aqueous organic solvents respectively. These rates determined at $25.0{ }^{\circ} \mathrm{C}$ are listed in Table 1 , and the solvents include mixtures of aqueous fluoroalcohols.

For allyl chloroformate (3), there is a gradual increment in the specific rate of solvolysis with the increase in water content in mixtures with ethanol, methanol, acetone, and TFE. In the aqueous HFIP mixtures, the rate of 3 is the greatest in the very strongly hydrogen bonding 97\% HFIP. The $80 \%$ $\mathrm{EtOH}$ and $100 \% \mathrm{MeOH}$ values documented in Table 1 for 3 are within the margin of error when compared to those reported at $25.0{ }^{\circ} \mathrm{C}$ by Koh and Kang [60]. However our ethanolyses rate for 3 is almost three times faster than the previously reported value [60]. We have since repeated this determination six times using different batches of purified solvent to make sure that our reported EtOH value is correct.

The rates of solvolysis for vinyl chloroformate (4) also rise as the water content of the binary aqueous mixtures increase. In the TFE-EtOH mixtures, the rise in the specific rates intensifies with the increase in ethanol content. This illustrates the importance of the role of solvent nucleophilicity at the developing transition state for solvolyses in these mixtures. 
In Table 1, we also list the $25.0{ }^{\circ} \mathrm{C}$ values for phenyl (1) [21-23,26,27] and benzyl (5) [56] chloroformate that are obtained from the literature for the common solvents that 3 and 4 were studied in. In the TFE-EtOH mixtures and in the aqueous EtOH, $\mathrm{MeOH}$, and acetone solvents, a general trend of $k_{4}>k_{1}>k_{5} \approx k_{3}$ is observed. In these particular solvents, 1 and 5 have been shown to solvolyze by a bimolecular addition-elimination process via the formation of a tetrahedral intermediate $[22,23,27,56]$.

Table 1. Specific rates of solvolysis $(k)$ of 3 and 4 in several binary solvents at $25.0{ }^{\circ} \mathrm{C}$ indicated by $(\mathrm{T})$ when determined by titration, otherwise determined by conductivity measurements, and literature values for $1,5, N_{T}$ and $Y_{C l}$.

\begin{tabular}{|c|c|c|c|c|c|c|}
\hline Solvent $(\%)^{a}$ & $\begin{array}{c}1^{\mathrm{b}} \\
10^{5} k, \mathrm{~s}^{-1}\end{array}$ & $\begin{array}{c}3(\mathrm{~T}) \\
10^{5} \mathrm{k}, \mathrm{s}^{-1 \mathrm{c}}\end{array}$ & $\begin{array}{c}4 \\
10^{5} k, s^{-1 c}\end{array}$ & $\begin{array}{c}5^{d} \\
10^{5} k, s^{-1}\end{array}$ & $N_{T}^{\mathrm{e}}$ & $Y_{C l}{ }^{\mathrm{f}}$ \\
\hline $100 \% \mathrm{EtOH}$ & 260 & $11.1 \pm 0.16$ & $742 \pm 1$ & 5.16 & 0.37 & -2.50 \\
\hline $90 \% \mathrm{EtOH}$ & 389 & $13.4 \pm 0.7$ & $921 \pm 3$ & 12.9 & 0.16 & -0.90 \\
\hline $80 \% \mathrm{EtOH}$ & 503 & $14.7 \pm 0.4$ & $1252 \pm 19$ & 17.7 & 0.00 & 0.00 \\
\hline $70 \% \mathrm{EtOH}$ & 546 & $18.0 \pm 0.6$ & & 21.5 & -0.20 & 0.78 \\
\hline $60 \% \mathrm{EtOH}$ & 658 & $23.4 \pm 0.9$ & & 25.6 & -0.38 & 1.38 \\
\hline $100 \% \mathrm{MeOH}$ & 695 & $12.5 \pm 0.7$ & $1485 \pm 13$ & 18.8 & 0.17 & -1.20 \\
\hline $90 \% \mathrm{MeOH}$ & 1290 & $28.4 \pm 1.5$ & $2331 \pm 42$ & 38.4 & -0.01 & -0.20 \\
\hline $80 \% \mathrm{MeOH}$ & 1670 & $36.7 \pm 2.0$ & $3500 \pm 55$ & 55.4 & -0.06 & 0.67 \\
\hline $60 \% \mathrm{MeOH}$ & 2220 & $38.5 \pm 0.8$ & & & -0.54 & 2.07 \\
\hline $90 \%$ Acetone & 23.8 & & $146 \pm 2$ & & -0.35 & -2.39 \\
\hline $80 \%$ Acetone & 68.8 & & $260 \pm 4$ & 2.13 & -0.37 & -0.80 \\
\hline $70 \%$ Acetone & 125 & $2.79 \pm 0.14$ & $365 \pm 3$ & 4.23 & -0.42 & 0.17 \\
\hline $60 \%$ Acetone & 195 & $3.41 \pm 0.14$ & & 7.62 & -0.52 & 1.00 \\
\hline $97 \%$ TFE $(w / w)$ & 0.0570 & $0.166 \pm 0.016$ & & 1.93 & -3.30 & 2.83 \\
\hline $90 \% \operatorname{TFE}(w / w)$ & 1.15 & $0.317 \pm 0.017$ & $26.2 \pm 0.3(\mathrm{~T})$ & 2.37 & -2.55 & 2.85 \\
\hline $80 \%$ TFE $(w / w)$ & 7.02 & & $50.5 \pm 1.2$ & 3.44 & -2.19 & 2.90 \\
\hline $70 \%$ TFE $(w / w)$ & 17.4 & $0.467 \pm 0.021$ & $88.6 \pm 0.9$ & 4.82 & -1.98 & 2.96 \\
\hline $50 \%$ TFE $(w / w)$ & 63.5 & $0.531 \pm 0.022$ & & 9.39 & -1.73 & 3.16 \\
\hline $80 \mathrm{~T}-20 \mathrm{E}$ & 2.43 & $0.434 \pm 0.016$ & $31.6 \pm 0.1(\mathrm{~T})$ & 0.692 & -1.76 & 1.89 \\
\hline $60 \mathrm{~T}-40 \mathrm{E}$ & 17.5 & $0.723 \pm 0.050$ & $43.2 \pm 0.1(\mathrm{~T})$ & 0.993 & -0.94 & 0.63 \\
\hline $40 \mathrm{~T}-60 \mathrm{E}$ & 57.7 & & $178 \pm 1$ & 2.19 & -0.34 & -0.48 \\
\hline $20 \mathrm{~T}-80 \mathrm{E}$ & 169 & & $696 \pm 1$ & 3.90 & 0.08 & -1.42 \\
\hline 97\% HFIP $(w / w)$ & $14.8 \times 10^{-4}$ & $1.80 \pm 0.12$ & & 13.8 & -5.26 & 5.17 \\
\hline $90 \%$ HFIP $(w / w)$ & 0.166 & $0.362 \pm 0.023$ & & 11.5 & -3.84 & 4.41 \\
\hline $70 \%$ HFIP $(w / w)$ & 10.5 & $0.553 \pm 0.021$ & $49.5 \pm 0.2$ & 11.3 & -2.94 & 3.83 \\
\hline
\end{tabular}

${ }^{a}$ Substrate concentration of $c a .0 .0052 \mathrm{M}$; binary solvents on a volume-volume basis at $25.0{ }^{\circ} \mathrm{C}$, except for TFE- $\mathrm{H}_{2} \mathrm{O}$ and HFIP- $\mathrm{H}_{2} \mathrm{O}$ solvents which are on a weight-weight basis. T-E are TFE-ethanol mixtures; b References [22,23,27]; ${ }^{c}$ With associated standard deviation; ${ }^{d}$ Reference [56]; ${ }^{\mathrm{e}}$ References [17,18]; ${ }^{\mathrm{f}}$ References [11-16].

For 3, in 30 solvents examined (excluding the TFE-EtOH mixtures), Koh and Kang claimed [60] that a predominant bimolecular $\mathrm{S}_{\mathrm{N}} 2$ type mechanism was occurring since the $\mathrm{G}-\mathrm{W}$ analysis of their rates for 3 [at $35.0^{\circ} \mathrm{C}$ and using Equation (2)] resulted in an $l$ value of 0.93 , an $m$ value of 0.41 , and 
$R=0.964$. In Table 2, we have reported the results that we obtained for substrates $\mathbf{3}$, and $\mathbf{4}$ after a multiple correlation analyses employing Equation (2).

Table 2. Correlation of the specific rates of reaction of $\mathbf{3}$, and $\mathbf{4}$, using Equation (2).

\begin{tabular}{ccccccc}
\hline Substrate & $\boldsymbol{n}^{\mathbf{a}}$ & $\boldsymbol{l}^{\mathbf{b}}$ & $\boldsymbol{m}^{\mathbf{b}}$ & $\boldsymbol{c}^{\mathbf{c}}$ & $\boldsymbol{R}^{\mathbf{d}}$ & $\boldsymbol{F}^{\mathbf{e}}$ \\
\hline $3^{\mathrm{f}}$ & $35^{\mathrm{g}}$ & $0.98 \pm 0.06$ & $0.44 \pm 0.03$ & $-0.04 \pm 0.05$ & 0.944 & 132 \\
& $28^{\mathrm{h}}$ & $1.43 \pm 0.13$ & $0.52 \pm 0.03$ & $0.10 \pm 0.06$ & 0.954 & 127 \\
& $7^{\mathrm{i}}$ & $0.93 \pm 0.12$ & $0.66 \pm 0.14$ & $-0.84 \pm 0.30$ & 0.974 & 36 \\
$3^{\mathrm{j}}$ & $12^{\mathrm{k}}$ & $1.46 \pm 0.19$ & $0.37 \pm 0.09$ & $0.10 \pm 0.08$ & 0.943 & 37 \\
& $12^{1}$ & $1.78 \pm 0.18$ & $0.43 \pm 0.07$ & $0.14 \pm 0.06$ & 0.965 & 61 \\
4 & $12^{\mathrm{m}}$ & $1.67 \pm 0.19$ & $0.31 \pm 0.07$ & $0.10 \pm 0.09$ & 0.941 & 35 \\
& $5^{\mathrm{n}}$ & $0.80 \pm 0.03$ & $0.59 \pm 0.01$ & $-1.31 \pm 0.03$ & 0.999 & 578 \\
\hline
\end{tabular}

${ }^{\mathrm{a}} n$ is the number of solvents; ${ }^{\mathrm{b}}$ With associated standard error; ${ }^{\mathrm{c}}$ Accompanied by standard error of the estimate; ${ }^{\mathrm{d}}$ Correlation coefficient; ${ }^{\mathrm{e}} \mathrm{F}$-test value; ${ }^{\mathrm{f}}$ Results obtained using the specific rate data from reference [60] at $35.0^{\circ} \mathrm{C} ;{ }^{\mathrm{g}}$ All available solvents; ${ }^{\mathrm{h}}$ Excluding the data points in the TFE (aq) and HFIP (aq) solutions listed in reference [60]; ${ }^{i}$ Just the TFE (aq) and HFIP (aq) data points in reference [60]; ${ }^{\mathrm{j}}$ This work at $25.0{ }^{\circ} \mathrm{C}$. ${ }^{\mathrm{k}}$ This work, excluding the data points in all the TFE (aq) and HFIP (aq) solutions; ${ }^{1}$ This work, excluding the data points in 80T-20E, 97\%-70\% TFE (aq) and 97\%-70\% HFIP (aq) solutions; ${ }^{\mathrm{m}}$ This work, excluding $80 \mathrm{~T}-20 \mathrm{E}, 70 \%$ HFIP, and the three TFE (aq) data points; ${ }^{\mathrm{n}}$ This work, just $80 \mathrm{~T}-20 \mathrm{E}, 70 \%$ HFIP, and $90 \%-70 \%$ TFE.

A reanalysis using Equation (2) of the published data for 3 in all 35 solvents studied at $35.0{ }^{\circ} \mathrm{C}$ resulted in an $l$ value of $0.98 \pm 0.06$, an $m$ value of $0.44 \pm 0.03, c=-0.04 \pm 0.05, R=0.945$, and a $F$-test value of 132 (reported in Table 2). These values are essentially the same as those reported by Koh and Kang for 30 solvents [60] and this statistical outcome demonstrates that in this particular case there is little gained by for excluding the TFE-EtOH solvents in such a G-W analysis.

In the highly ionizing aqueous HFIP and aqueous TFE binary mixtures a nucleophilic addition-elimination mechanism was still shown to dominate in $\mathbf{1}[22,23,27]$, while a solvolysis-decomposition type process after formation of a cationic transition state was proposed for 5 [56]. On the other hand for the alkenyl containing isopropenyl chloroformate (2), it was proposed [57] that a superimposed unimolecular $\left(S_{N} 1\right)$ type ionization process was making a significant contribution in $97 \%-70 \%$ HFIP, and $97 \%$ TFE due to the formation of a resonance stabilized intermediate carbocation.

Figure 2. Possible carbonyl cation resonance structures for compounds $\mathbf{3}$ and $\mathbf{4}$.<smiles>C=CCOC(=O)OC</smiles>

3a 3b<smiles>C=CCOC=C=O</smiles>

$3 \mathbf{c}$<smiles>C=COC#[O+]</smiles>

$4 a$<smiles>C=COC(C)=O</smiles>

4b<smiles>C=C[O+]=C=O</smiles>

$4 c$ 
In Figure 2 (above), we show the important resonance contributors for the two alkenoxy carbonyl cations considered in this study. These delocalized structures attest to the immense possibility that like 2, 3 and 4 could show significant unimolecular $S_{N} 1$ character in the highly ionizing aqueous fluoroalcohol mixtures.

For 3 at $35.0{ }^{\circ} \mathrm{C}$ a G-W analysis obtained on the exclusion of the data points [60] in the TFE (aq) and HFIP (aq) solutions resulted in, $l=1.43 \pm 0.13, m=0.52 \pm 0.03, c=0.10 \pm 0.06, R=0.954$, and $F=127$. These $l$ and $m$ values are within the range of those obtained for $\mathbf{1}$, strongly suggesting that a carbonyl addition would be the favored process in the remaining 28 solvents analyzed. In just the seven TFE (aq) and HFIP (aq) mixtures, we obtain $0.93 \pm 0.12,0.66 \pm 0.14,-0.84 \pm 0.30,0.974$, and 36 for $l, m, c, R$, and $F$ respectively. This $l / m$ ratio of 1.41 obtained for the TFE and HFIP mixtures is similar in magnitude to that previously observed for the solvolyses of acetyl chloride $(\mathrm{l} / \mathrm{m}$ ratio of 1.19) [74] and 4-morpholinecarbonyl [75] chloride ( $l / m$ ratio of 1.12). Such ranges in $l / m$ ratios were reported to articulate unimolecular ionization $\left(\mathrm{S}_{\mathrm{N}} 1\right)$ pathways with considerable nucleophilic solvation at the developing carbocation [74,75].

In this study, we document the rates obtained for allyl chloroformate (3) at $25.0{ }^{\circ} \mathrm{C}$ (Table 1). A G-W analysis (Table 2) for 12 solvents excluding the aqueous fluoroalcohol mixtures (TFE and HFIP), show $l=1.46 \pm 0.19, m=0.37 \pm 0.09, c=0.10 \pm 0.08, R=0.943$, and $F=37$. In order to identify the exact ionizing solvents (with high fluoroalcohol content) where the mechanisms displayed the greatest overlapping traits, we then carried out a G-W analysis in a different set of 12 solvents which eliminated the data points in 80T-20E, 97\%-70\% TFE (aq) and 97\%-70\% HFIP (aq). We obtained $1.78 \pm 0.18,0.43 \pm 0.07,0.14 \pm 0.06,0.965$, and 61 , for $l, m, c, R$, and $F$ respectively (Table 2). For these 12 solvents, the much improved $R$ and $F$-test values advocate that these particular $l(1.78)$ and $m$ (0.43) values obtained are the deciding contributions that indicate the amounts of bond making and bond breaking at the tetrahedral transition state for 3 .

In Figure 3, a plot of $\log \left(k / k_{\mathrm{o}}\right)$ for 3 at $25.0{ }^{\circ} \mathrm{C}$ against $1.78 N_{\mathrm{T}}+0.43 Y_{\mathrm{Cl}}$ is shown. The seven fluoroalcohol containing solvents (97\%-90\% HFIP, 97\%-70\% TFE, and 80T-20E) are excluded from the G-W calculation but are added to the plot to show the extent of their deviation from the line-of-best-fit.

Figure 3. The plot of $\log \left(k / k_{\mathrm{o}}\right)$ for 3 at $25.0{ }^{\circ} \mathrm{C}$ against $1.78 N_{\mathrm{T}}+0.43 Y_{\mathrm{Cl}}$.

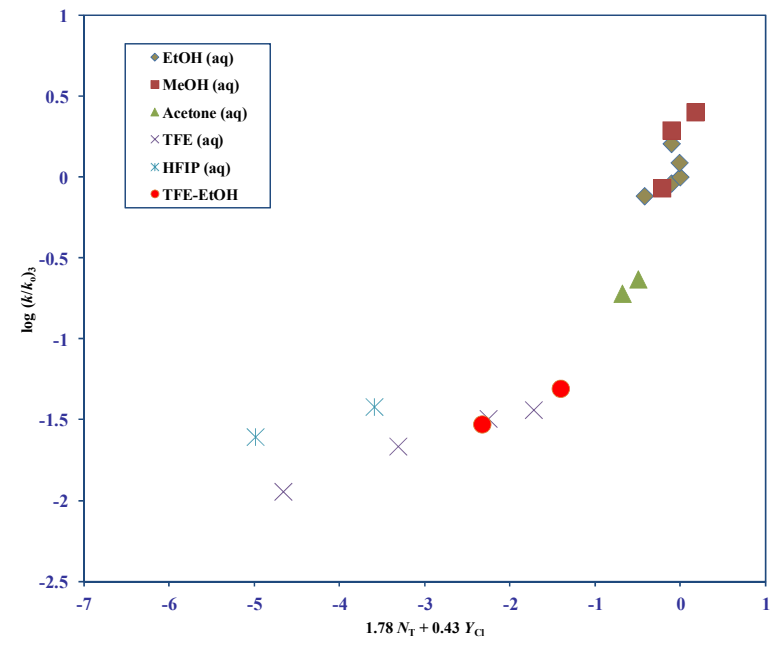


A G-W analysis of 4 in the 12 more nucleophilic solvents (excluding, 80T-20E, 70\% HFIP, and $90 \%-70 \%$ TFE) resulted in, $l=1.67 \pm 0.19, m=0.31 \pm 0.07, c=0.10 \pm 0.09, R=0.941$, and $F=35$ (Table 2). In Figure 4, a plot of $\log \left(k / k_{\mathrm{o}}\right)$ for 4 at $25.0^{\circ} \mathrm{C}$ against $1.67 N_{\mathrm{T}}+0.31 Y_{\mathrm{Cl}}$ is shown. The five excluded fluoroalcohol solvents were not included in the multiple regression analyses but were added on to demonstrate the intensity of the divergence from the regression line.

Figure 4. The plot of $\log \left(k / k_{\mathrm{o}}\right)$ for 4 at $25.0{ }^{\circ} \mathrm{C}$ against $1.67 N_{\mathrm{T}}+0.31 Y_{\mathrm{Cl}}$.

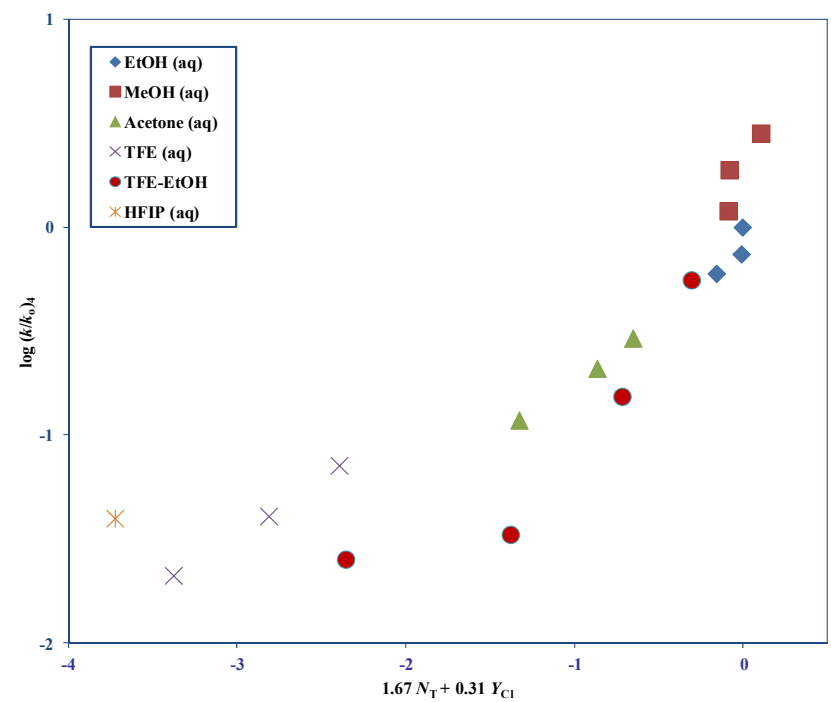

The $l$ and $m$ values obtained for $\mathbf{4}$ are numerically analogous to those calculated for $\mathbf{3}$. Such $l$ and $m$ values are consistent with the proposed bimolecular pathway through a tetrahedral intermediate formed by the rate determining addition of the solvent at the carbonyl carbon. The slightly reduced $m$ values for 3 and 4 could imply a decreased need for solvation of the developing negative charge on the carbonyl oxygen in the $\mathrm{sp}^{3}$ hybridized tetrahedral transition state.

For 4, in the five remaining fluoroalcohol mixtures (80T-20E, 70\% HFIP, and $90 \%-70 \%$ TFE) we get $0.80 \pm 0.03,0.59 \pm 0.01,(-1.31) \pm 0.03,0.999$, and 578 for $l, m, c, R$, and $F$ respectively. This $l / m$ ratio is 1.36. For 3 and $\mathbf{4}$ the amount of dispersion (Figures 3 and 4) observed in these fluoroalcohols and the very similar fractional contributions towards the sensitivities of solvent nuclophilicity $(l)$ and solvent ionizing power $(m)$, suggests the definitive probability of virtually identical reaction channels occurring.

The ethanolyses rate of isopropenyl chloroformate (2) at $25.0{ }^{\circ} \mathrm{C}$ was reported to be $(110 \pm 6) \times 10^{-5}$ [57]. A comparison of this pure EtOH data point together with the other values listed in Table 1 show, $k_{4}>k_{2}>>k_{1}>k_{5} \approx k_{3}$. Therefore in the pure alcohol and aqueous EtOH, $\mathrm{MeOH}$, and acetone solvents the increases in of the reaction rates observed with increasing solvent nucleophilicity can be attributed to the inductive ability of the different $\mathrm{R}$ groups in 1-5. Our observations based on the progression of the magnitude of these rates firmly indicates that the vinyl group in 4 (in these particular solvents) is very electron withdrawing via induction, and this especially holds true when its effect is compared to the responses observed due to the phenyl (1), benzyl (5), and allyl (3) groups. Consistent with this view vinyl has a polar substituent constant $\left(\sigma^{+}\right)$of 0.653 .

For 3 in deuterated $\mathrm{MeOH}$, a $k_{\mathrm{MeOH}} / k_{\mathrm{MeOD}}$ value of 2.16 was observed at $35.0{ }^{\circ} \mathrm{C}$ [60]. The large KSIE value observed for 3 , together with the large $l$ parameters in the more nucleophilic solvents 
calculated for $\mathbf{3}$ and $\mathbf{4}$, also indicate the strong possibility of general-base catalysis [21,26,30,32,33] to the nucleophilic attack in both 3 and 4.

For 2 in $97 \%$ HFIP and $97 \%$ TFE at $25.0{ }^{\circ} \mathrm{C}$, values of $3.23 \times 10^{-7}$ and $5.94 \times 10^{-7}$ are computed from the rates that we reported at different temperatures [57] and the Arrhenius equation. An examination of these calculated rates for 2 together with the rates for 1, 3, and 5 (listed in Table 1) in the highly ionizing and very strongly hydrogen bonding 97\% HFIP ( $Y_{\mathrm{Cl}}$ value of 5.17), we get $k_{5}>k_{3}>k_{2}>>k_{1}$. In comparison, in the moderately enhanced hydrogen bonding but less ionizing $97 \%$ TFE ( $Y_{\mathrm{Cl}}$ value of 2.83), the rate trend is $k_{5}>k_{3}>k_{2} \approx k_{1}$ (no rate value is available for 4 in 97\% HFIP and 97\% TFE). Even in 97\% HFIP and 97\% TFE, phenyl chloroformate (1) favors an addition-elimination pathway $[23,27]$ so it is not surprising that its rate in these two highly ionizing solvents is the slowest.

The 3-D images shown in Figure 5 are for a single resonance contributor formed within the developing acylium ion in 2-4. Our experimental evidence now suggests that such ionic species would be expected for 2-4 in the highly ionizing fluoroalcohols. A closer inspection reveals that in $3 \mathrm{a}^{\prime}$, the delocalized $\pi$ electron cloud of the alkenyl bond is far apart (and out of the plane) for any appreciable orbital overlap. However our investigation of the rate trends in 97\% HFIP and 97\% TFE show that the $\pi$ systems that are further away from the reaction center are indeed getting involved through positive hyperconjugation in the stabilization the cationic center. This rate sequence is consistent with the superiority in resonance stabilization that is to be expected within the benzylic carbocation since in these two solvents, 5 is said to favor a solvent-decomposition process with a loss of a $\mathrm{CO}_{2}$ molecule [56].

Figure 5. The 3-D images for the resonance conformers for the carbonyl cations of allyl chloroformate $\left(3 \mathrm{a}^{\prime}\right)$, vinyl chloroformate $\left(4 \mathrm{a}^{\prime}\right)$, and isopropenyl chloroformate $\left(2 \mathrm{a}^{\prime}\right)$ are shown.

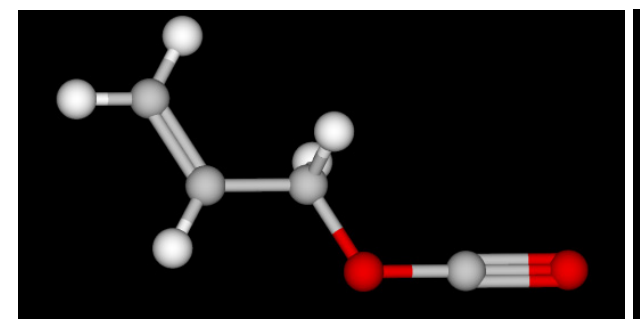

$3 \mathbf{a}^{\prime}$

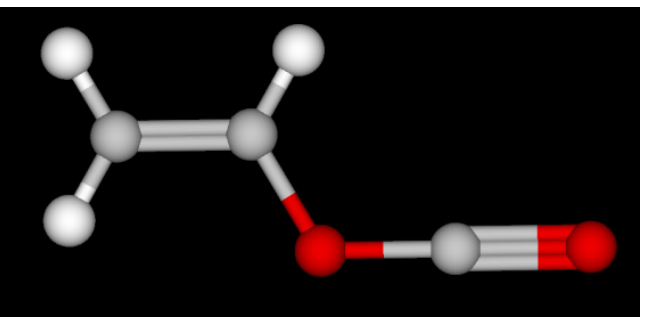

$4 a^{\prime}$

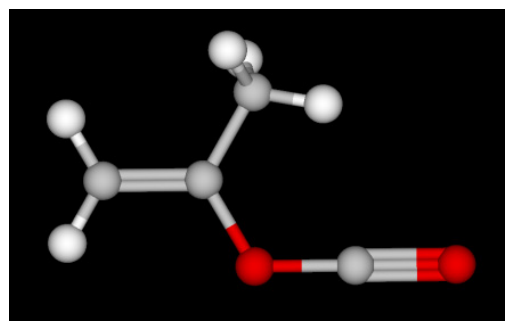

$2 \mathbf{a}^{\prime}$

In $70 \%$ HFIP, the only common fluoroalcohol-water mixture that $1-5$ are studied in at $25.0{ }^{\circ} \mathrm{C}$, a rate value of $(2.54 \pm 0.09) \times 10^{-5}$ is listed for 2 [57], and the rate trend is $k_{4}>k_{5} \approx k_{1}>k_{2}>k_{3}$. In $90 \%$ TFE, we observe $k_{4}>k_{5}>k_{1}>k_{3}$. Furthermore as solvent nucleophilicity increases with higher water 
content in going to $70 \% \mathrm{TFE}$, the rate trend moves towards $k_{4}>k_{1}>k_{5}>k_{3}$ and in $50 \% \mathrm{TFE}$, the rate order remains as $k_{1}>k_{5}>k_{3}$.

From these rate orders we can theorize that for the three alkenyl chloroformate ester solvolyses, the presence of dual side-by-side mechanisms is in response to pronounced competing mesomeric and inductive effects.

\section{Experimental Section}

The allyl chloroformate (97\%) and the vinyl chloroformate (99\%) were obtained from the Sigma-Aldrich Chemical Company and were used as received. Solvents were dried and purified as described previously [23]. A substrate concentration of approximately $0.005 \mathrm{M}$ in a variety of solvents was employed. The rate constants for the slow solvolytic reactions were determined by the trimetric method [23] and the faster rates were followed by conductance, at appropriate time intervals [74]. For some of the runs, calculation of the specific rates of solvolysis (first-order rate coefficients) was carried out by a process in which the conventional Guggenheim treatment [76] was modified [77] so as to give an estimate of the infinity titer, which was then used to calculate for each run a series of integrated rate coefficients. The specific rates and associated standard deviations, as presented in Table 1, are obtained by averaging all of the values from, at least, duplicate runs.

Multiple regression analyses were carried out using standard Microsoft statistical packages (Excel 2010; Microsoft Corporation: Redmond, WA, USA, 2010) and calculations for the Guggenheim treatments were performed on commercially available software (SigmaPlot, version 9.0; SYSTAT Software Inc.: San Jose, CA, USA, 2005). The 3-D images presented in Figure 4, were computed using the KnowItAll ${ }^{\circledR}$ Informatics System (ADME/Tox 2008; BioRad Laboratories: Philadelphia, PA, USA, 2008).

\section{Conclusions}

For the alkenyl chloroformate esters dual mesomeric and inductive effects are found to be in constant competition and their impact dominates the solvolyses of isopropenyl (2), allyl (3), and vinyl (4) chloroformate. In 4 as a result of the proximity of the $\pi$-electrons of the carbon-carbon double bond to the reaction center, its rates of reaction are very much faster when compared to those of $\mathbf{3}$ in all of the solvents studied.

For 3 and 4 G-W analyses using the two-term Equation (2) results in $l$ and $m$ sensitivities that forecast concurrent bimolecular tetrahedral carbonyl-addition and unimolecular ionization mechanisms. Such solvent-dependent synchronous mechanisms were also previously proposed for 2 [57]. For the alkenyl chloroformates 2-4, in pure $\mathrm{EtOH}$ (which is very nucleophilic and low ionizing) the addition-elimination mechanism dominates, and at the other extreme in 70\% HFIP, the ionization mechanism was found to be in control.

The molecular structure of $\mathbf{2}$ differs from that of $\mathbf{4}$ because of the presence of a methyl group on the $\alpha$-carbon of 4 . The hyperconjugative (electron releasing) ability of this methyl group has a considerable effect on the reaction rates, and hence $\mathbf{2}$ is slower than 4 in EtOH and 70\% HFIP. On the other hand, 2 is faster than 3 in EtOH and 70\% HFIP, but slower in 97\% HFIP and 97\% TFE. In the latter fluoroalcohol mixtures, the additional presence of a methyl group (shown in $\mathbf{2} \mathbf{a}^{\prime}$ ) cannot 
efficiently stabilize the developing cationic $\mathrm{S}_{\mathrm{N}} 1$ transition state and hence, $\mathbf{3}$ exhibits an accelerated rate in $97 \%$ HFIP and $90 \%$ TFE (when compared to 2 ).

\section{Acknowledgments}

This publication was made possible by the Delaware INBRE and Delaware EPSCoR programs. These programs are supported by grants from the National Center for Research Resources-NCRR (5P20RR016472-12) and the National Institute of General Medical Sciences-NIGMS (8 P20 GM103446-12) from the National Institutes of Health; a National Science Foundation (NSF) EPSCoR grant EPS-0814251; and the State of Delaware (DE). The DE-INBRE and DE-EPSCoR grants were obtained through the leadership of the University of Delaware and the authors sincerely appreciate their efforts. Additional support from an NSF ARI-R2 grant 0960503 received by M.J.D. is also acknowledged.

All five participating undergraduate students, Aaron Givens, Peter Lorchak, Abigail Greenwood, Stacey Gottschall, and Shannon Carter, received DE-INBRE or DE-EPSCoR supported Undergraduate Research Assistantships in the Wesley College Directed Research Program in Chemistry [78,79]. Aaron Givens also received a NASA/Delaware Space Grant (NNG05GO92H) Undergraduate Tuition Scholarship.

\section{Conflict of Interest}

The authors declare no conflict of interest.

\section{References}

1. Sartori, M. The War Gases. In Chemistry and Analysis; D. Van Nostrand Co., Inc.: New York, NY, USA, 1939.

2. Wellings, R.E. Poison war gases. School Sci. Math. 1942, 42, 331-339.

3. Trumpener, U. The road to Ypres: The beginnings of gas warfare in World War I. J. Mod. Hist. 1975, 47, 460-480.

4. Hazardous Materials Advisory Committee, United States Environmental Agency Science Advisory Board. Herbicide Report. Chemistry and Analysis. Environmental Effects. Agricultural and Other Applied Uses; Washington, DC, USA, May 1974.

5. Kevill, D.N. Chloroformate Esters and Related Compounds. In Acyl Halides; Patai, S., Ed.; John Wiley \& Sons, Ltd.: Chichester, UK, 1972.

6. Parrish, J.P.; Salvatore, R.N.; Jung, K.W. Perspectives of alkyl carbonates in organic synthesis. Tetrahedron 2000, 56, 8207-8237.

7. Banerjee, S.S.; Aher, N.; Patel, R.; Khandare, J. Poly(ethylene glycol)-prodrug conjugates: Concepts, design, and application. J. Drug Deliv. 2012, 2012, doi:10.1155/2012/103973.

8. Winstein, S.; Grunwald, E.; Jones, H.W. The correlation of solvolyses rates and the classification of solvolysis reactions into mechanistic categories. J. Am. Chem. Soc. 1951, 73, 2700-2707, and references there in. 
9. Bentley, T.W.; Garley, M.S. Correlations and predictions of solvent effects on reactivity: Some limitations of multi-parameter equations and comparisons with similarity models based on one solvent parameter. J. Phys. Org. Chem. 2006, 19, 341-349.

10. Kevill, D.N.; D'Souza, M.J. Sixty years of the Grunwald-Winstein equation: Development and recent applications. $J$. Chem. Res. 2008, 2008, 61-66, and references therein.

11. Bentley, T.W.; Carter, G.E. The $\mathrm{S}_{\mathrm{N}} 2-\mathrm{S}_{\mathrm{N}} 1$ spectrum. 4. Mechanism for solvolyses of tert-butyl chloride: A revised $Y$ scale of solvent ionizing power based on solvolyses of 1-adamantyl chloride. J. Am. Chem. Soc. 1982, 104, 5741-5747.

12. Bentley, T.W.; Llewellyn, G. $Y_{\mathrm{x}}$ scales of solvent ionizing power. Prog. Phys. Org. Chem. 1990, 17, 121-158.

13. Kevill, D.N.; D'Souza, M.J. Additional $Y_{\mathrm{Cl}}$ values and correlation of the specific rates of solvolysis of tert-butyl chloride in terms of $N_{\mathrm{T}}$ and $Y_{\mathrm{Cl}}$ scales. J. Chem. Res. Synop. 1993, 174-175.

14. Lomas, J.S.; D’Souza, M.J.; Kevill, D.N. Extremely large acceleration of the solvolysis of 1-adamantyl chloride upon incorporation of a spiro adamantane substituent: Solvolysis of 1-chlorospiro[adamantane-2, 2'-adamantane]. J. Am. Chem. Soc. 1995, 117, 5891-5892.

15. Kevill, D.N.; Ryu, Z.H. Additional solvent ionizing power values for binary water-1,1,1,3,3,3,-hexafluoro-2-propanol solvents. Int. J. Mol. Sci. 2006, 7, 451-455.

16. Schadt, F.L.; Bentley, T.W.; Schleyer, P.R. The $\mathrm{S}_{\mathrm{N}} 2-\mathrm{S}_{\mathrm{N}} 1$ spectrum. 2. Quantitative treatments of nucleophilic solvent assistance. A scale of solvent nucleophilicities. J. Am. Chem. Soc. 1976, 98, 7667-7674.

17. Kevill, D.N.; Anderson, S.W. An improved scale of solvent nucleophilicity based on the solvolysis of the $S$-methyldibenzothiophenium Ion. J. Org. Chem. 1991, 56, 1845-1850.

18. Kevill, D.N. Development and Uses of Scales of Solvent Nucleophilicity. In Advances in Quantitative Structure-Property Relationships; Charton, M., Ed.; JAI Press: Greenwich, CT, USA, 1996; Volume 1, pp. 81-115.

19. Queen A. Kinetics of the hydrolysis of acyl chlorides in pure water. Can. J. Chem. 1967, 45, 1619-1629.

20. Butler, A.R.; Robertson, I.H.; Bacaloglu, R. Kinetics and mechanism of the base-catalysed hydrolysis of some substituted phenyl chloroformates. J. Chem. Soc. Perkin Trans 2 1974, 1733-1736.

21. Yew, K.H.; Koh, H.J.; Lee, H.W.; Lee, I. Nucleophilic substitution reactions of phenyl chloroformate. J. Chem. Soc. Perkin Trans 2 1995, 2263-2268.

22. Koo, I.S.; Yang, K.; Kang, K.; Oh, H.K.; Lee, I. Stoichiometric solvation effects. Product-rate correlation for the solvolyses of phenyl chloroformate in alcohol-water mixtures. Bull. Korean Chem. Soc. 1996, 17, 520-524.

23. Kevill, D.N.; D'Souza, M.J. Correlation of the rates of solvolysis of phenyl chloroformate. J. Chem. Soc. Perkin Trans. 2 1997, 1721-1724.

24. Koo, I.S.; Yang, K.; Koo, J.C.; Park, J.-K.; Lee, I. Stoichiometric solvation effects. Part 4. Product-rate correlations for solvolyses of $p$-methoxyphenyl chloroformate in alcohol-water mixtures. Bull. Korean Chem. Soc. 1997, 18, 1017-1021. 
25. Koo, I.S.; Yang, K.; Kang, K.; Lee, I.; Bentley, T.W. Stoichiometric solvation effects. Part 3. Product-rate correlations for solvolyses of $p$-nitrophenyl chloroformate in alcohol-water mixtures. J. Chem. Soc. Perkin Trans 2 1998, 1179-1183.

26. Koo, I.S.; Yang, K.; Kang, K.; Lee, I. Transition-state variation in the solvolyses of para-substituted phenyl chloroformates in alcohol-water mixtures. Bull. Korean Chem. Soc. 1998, 19, 968-973.

27. Kevill, D.N.; Koyoshi, F.; D'Souza, M.J. Correlation of the specific rates of solvolysis of aromatic carbamoyl chlorides, chloroformates, chlorothionoformates, and chlorodithioformates revisited. Int. J. Mol. Sci. 2007, 8, 346-352.

28. D’Souza, M.J.; Reed, D.; Koyoshi, F.; Kevill, D.N. Consideration of the factors influencing the specific rates of solvolysis of p-methoxyphenyl chloroformate. Int. J. Mol. Sci. 2007, 8, 788-796.

29. Bentley, T.W. Structural effects on the solvolytic reactivity of carboxylic and sulfonic acid chlorides. Comparisons with gas-phase data for cation formation. J. Org. Chem. 2008, 73, 6251-6257.

30. D’Souza, M.J.; Shuman, K.E.; Carter, S.E.; Kevill, D.N. Extended Grunwald-Winstein analysis - LFER used to gauge solvent effects in $p$-nitrophenyl chloroformate solvolysis. Int. J. Mol. Sci. 2008, 9, 2231-2242.

31. D’Souza, M.J.; Knapp, J.A.; Fernandez-Bueno, G.A.; Kevill, D.N. Use of LFERs to elucidate the mechanisms of reaction of a $\gamma$-methyl- $\beta$-alkynyl and an ortho-substituted aryl chloroformate ester. Int. J. Mol. Sci. 2012, 13, 665-682.

32. Koo, I.S.; Lee, J.S.; Yang, K.; Kang, K.; Lee, I. The studies on substituent and kinetic solvent isotope effect in solvolyses of phenyl chloroformates. Bull. Korean Chem. Soc. 1999, 20, 573-576.

33. Bentley, T.W.; Harris, H.C.; Ryu, Z.-H.; Lim, G.T.; Sung, D.D.; Szajda, S.R. Mechanisms of solvolyses of acid chlorides and chloroformates. Chloroacetyl and phenylacetyl chloride as similarity models. J. Org. Chem. 2005, 70, 8963-8970.

34. Castro, E.A.; Ruiz, M.G.; Salinas, S.; Santos, J.G. Kinetics and mechanism of the aminolysis of phenyl and 4-nitrophenyl chloroformates in aqueous solution. J. Org. Chem. 1999, 64, 4817-4820.

35. Castro, E.A.; Ruiz, M.G.; Santos, J.G. Structure-reactivity correlations in the aminolysis of aryl chloroformates. Int. J. Chem. Kinet. 2001, 281-287.

36. Crugerias, J.; Leis, J.R.; Ríos, A. Micellar effects on the spontaneous hydrolysis of phenyl chloroformate. J. Chem. Educ. 2001, 78, 1538-1540.

37. Muňoz, M.; Rodríguez, A.; Graciani, M.M.; Moyá, M.L. Micellar medium effects on the hydrolysis of phenyl chloroformate in ionic, zwitterionic, nonionic, and mixed micellar solutions. Int. J. Chem. Kinet. 2002, 34, 445-451.

38. Graciani, M.d.M.; Rodríguez, A.; Muňoz, M.; Moyá, M. Water-ethylene glycol alkyltrimethylammonium bromide micellar solutions as reaction media: Study of spontaneous hydrolysis of phenyl chloroformate. Langmuir 2003, 19, 8685-8691.

39. Moon, D.H.; Seong, M.H.; Kyong, J.B.; Lee, Y.; Lee, Y.-W. Correlation of the rates of solvolysis of 1- and 2-naphthyl chloroformates using the extended Grunwald-Winstein equation. Bull. Korean Chem. Soc. 2011, 32, 2413-2417. 
40. Kevill, D.N.; Kim, J.C.; Kyong, J.B. Correlation of the rates of solvolysis of methyl chloroformate with solvent properties. J. Chem. Res. Synop. 1999, 150-151.

41. Kevill, D.N.; D'Souza, M.J. Concerning the two reaction channels for the solvolyses of ethyl chloroformate and ethyl chlorothioformate. J. Org. Chem. 1998, 63, 2120-2124.

42. Kevill, D.N.; D'Souza, M.J. Correlation of the Rates of Solvolyses of $n$-Octyl Fluoroformate and a Comparison with $n$-Octyl Chloroformate Solvolyses. J. Chem. Soc. Perkin Trans. 2 2002, 240-243.

43. Kyong, J.B.; Won, H.; Kevill, D.N. Application of the extended Grunwald-Winstein equation to solvolyses of $n$-propyl chloroformate. Int. J. Mol. Sci. 2005, 6, 87-96.

44. D’Souza, M.J.; McAneny, M.J.; Kevill, D.N.; Kyong, J.B.; Choi, S.H. Kinetic evaluation of the solvolysis of isobutyl chloro- and chlorothioformate esters. Beilstein J. Org. Chem. 2011, 7, $543-552$.

45. D'Souza, M.J.; Carter, S.E.; Kevill, D.N. Correlation of the rates of solvolysis of neopentyl chloroformate-A recommended protecting agent. Int. J. Mol. Sci. 2011, 12, 1161-1174.

46. Seong, M.H.; Choi, S.H.; Lee, Y.W.; Kyong, J.B.; Kim, D.K.; Kevill, D.N. Correlation of the rates of solvolysis of methyl fluoroformate using the extended Grunwald-Winstein equation. Bull. Korean Chem. Soc. 2009, 30, 2408-2412.

47. Seong, M.H.; Kyong, J.B.; Kim, D.K.; Kevill, D.N. Application of the extended Grunwald-Winstein equation to solvolyses of $n$-propyl fluoroformate and a consideration of leaving group effects. Bull. Korean Chem. Soc. 2008, 29, 1747-1751.

48. Lee, S.H.; Rhu, C.J.; Kyong, J.B.; Kim, D.K.; Kevill, D.N. Correlation of the rates of solvolysis of isopropyl fluoroformate using the extended Grunwald-Winstein equation. Bull. Korean Chem. Soc. 2007, 28, 657-661.

49. Lee, Y.W.; Seong, M.H.; Kyong, J.B.; Kevill, D.N. Correlation of the specific rates of solvolysis of $t$-butyl fluoroformate using the extended Grunwald-Winstein equation. Bull. Korean Chem. Soc. 2010, 31, 3366-3370.

50. Lee, Y.; Park, K.-H.; Seong, M.H.; Kyong, J.B.; Kevill, D.N. Correlation of the rates of solvolysis of $i$-butyl fluoroformate and a consideration of leaving group effects. Int. J. Mol. Sci. 2012, 12, 7806-7817.

51. Kevill, D.N.; D'Souza, M.J. Correlation of the rates of solvolysis of benzoyl fluoride and a consideration of leaving-group effects. J. Org. Chem. 2004, 69, 7044-7050.

52. Bentley, T.W. Concurrent pathways to explain solvent and substituent effects for solvolyses of benzoyl chlorides in ethanol-trifluoroethanol mixtures. Arch. Org. Chem. 2012, 25-34.

53. D’Souza, M.J.; Reed, D.N.; Erdman, K.J.; Kyong, J.B.; Kevill, D.N. Grunwald-Winstein analysis-Isopropyl chloroformate solvolysis revisited. Int. J. Mol. Sci. 2009, 10, 862-879.

54. Kyong, J.B.; Yoo, J.-S.; Kevill, D.N. Solvolysis-decomposition of 2-adamantyl chloroformate: Evidence for two reaction pathways. J. Org. Chem. 2003, 68, 3425-3432.

55. Kevill, D.N.; Kyong, J.B.; Weitl, F.L. Solvolysis-decomposition of 1-adamantyl chloroformate: Evidence for ion pair return in 1-adamantyl chloride solvolysis. J. Org. Chem. 1990, 55, 4304-4311.

56. Kyong, J.B.; Park, B.-C.; Kim, C.-B.; Kevill, D.N. Rate and product studies with benzyl and p-nitrobenzyl chloroformates under solvolytic conditions. J. Org. Chem. 2000, 65, 8051-8058. 
57. D’Souza, M.J.; Shuman, K.E.; Omondi, A.O.; Kevill, D.N. Detailed analysis for the solvolysis of isopropenyl chloroformate. Eur. J. Chem. 2011, 2, 130-135.

58. D’Souza, M.J.; Darrington, A.M.; Kevill, D.N. A study of solvent effects in the solvolysis of propargyl chloroformate. ISRN Org. Chem. 2011, 2011, 767141:1-767141:6.

59. Hook, A.L; Chang, C.Y.; Yang, J.; Luckett, J.; Cockayne, A.; Atkinson, S.; Mei, Y.; Bayston, R.; Irvine, D.J.; Langer, R.; et al. Combinatorial discovery of polymers resistant to bacterial attachment. Nat. Biotechnol. 2012, 30, 868-875.

60. Koh, H.J.; Kang, S.J. Rate and product studies on the solvolyses of allyl chloroformate. Bull. Korean Chem. Soc. 2012, 33, 4117-4121.

61. Li, C.J. Organic reactions in aqueous media with a focus on carbon-carbon bond formations: A decade update. Chem. Rev. 2005, 105, 3095-3165.

62. Kevill, D.N.; Rissman, T.J. Correlation of the rates of solvolysis of allyl and benzyl arenesulphonates. J. Chem. Soc. Perkin Trans 2 1984, 717-720.

63. Kevill, D.N.; D'Souza, M.J. Correlation of the rates of solvolysis of benzoyl chloride and derivatives using extended forms of the Grunwald-Winstein equation. J. Phys. Org. Chem. 2002, $15,881-888$.

64. D'Souza, M.J.; Darrington, A.M.; Kevill, D.N. On the importance of the aromatic ring parameter in studies of the solvolyses of cinnamyl and cinnamoyl halides. Org. Chem. Int. 2010, 2010, 13050621-13050629.

65. Bentley, T.W.; Harris, H.C. Solvolyses of benzoyl chlorides in weakly nucleophilic media. Int. J. Mol. Sci. 2011, 12, 4805-4818.

66. Olah, G.; Mayr, H. Stable Carbocations. 198. Formation of allyl cations via protonation of alkenes in magic acid solution. Evidence of 1,2-alkyl shifts in the intermediate vinyl cations. J. Am. Chem. Soc. 1976, 78, 7333-7340.

67. Imhoff, M.A.; Summerville, R.H.; Schleyer, P.v.R.; Martinez, A.G.; Hanack, M.; Dueber, T.E.; Stang, P.J. Preparation and solvolysis of vinyl triflates. IV. Rearrangements involving simple vinyl cations generated by solvolysis. J. Am. Chem. Soc. 1970, 92, 3802-3804.

68. Summerville, R.H.; Senkler, C.A.; Schleyer, P.R.; Dueber, T.E.; Stang, P.J. Solvolysis of vinyl triflates. Effects of alkyl substituents, solvents, and added nucleophiles. J. Am. Chem. Soc. 1974, 96, 1100-1110.

69. Summerville, R.H.; Schleyer, P.R. Stereochemistry of vinyl cations and vinyl substitutions. J. Am. Chem. Soc. 1974, 96, 1100-1120.

70. Yates, K.; Mandrapilias, G. Vinyl cation intermediates in solvolytic and electrophilic reactions. 1. Solvolysis of $\alpha$-arylvinyl derivatives. J. Org. Chem. 1980, 45, 3892-3902.

71. Jia, Z.S.; Ottosson, H.; Zeng, X.; Thibblin, A. The role of ion-molecule pairs in solvolysis reactions. Nucleophilic addition of water to a tertiary allylic carbocation. J. Org. Chem. 2002, 67, $182-187$.

72. Okuyama, T. Solvolysis of vinyl iodonium salts. New insights into vinyl cation intermediates. Acc. Chem. Res. 2002, 35, 12-18.

73. Fujita, M.; Yamamoto, A.; Sugimura, T.; Okuyama, T. Solvolysis of chiral cyclohexylidenemethyl triflate. Evidence against a primary vinyl cation intermediate. $J$. Phys. Org. Chem. 2002, 15, 550-555. 
74. D’Souza, M.J.; Ryu, Z.H.; Park, B.-C.; Kevill, D.N. Correlation of the rates of solvolysis of acetyl chloride and $\alpha$-substituted derivatives. Can. J. Chem. 2008, 86, 359-367.

75. Kevill, D.N.; Casamassa, A.J.; D’Souza, M.J. Rates and product selectivities for the solvolyses of 4-(chloroformyl)morpholine. J. Chem. Res. (S) 1996, 472-473.

76. Frost, A.A.; Pearson, R.G. Kinetics and Mechanism-a Study of Homogeneous Chemical Reactions, 2nd ed.; Wiley: New York, NY, USA, 1961; pp. 49-50.

77. Kevill, D.N.; Abduljaber, M.H. Correlation of the rates of solvolysis of cyclopropylcarbinyl and cyclobutyl bromides using the extended Grunwald-Winstein equation. J. Org. Chem. 2000, 65, 2548-2554.

78. D’Souza, M.J.; Dwyer, P.; Allison, B.E.; Miller, J.M.; Drohan, J. Wesley College ignites potential with undergraduate student research program. Counc. Undergrad Res. 2011, 32, 41-45.

79. D’Souza, M.J.; Wang, Q. Inter-institutional partnerships propel a successful undergraduate research program in chemistry. J. Coll. Teach. Learn. 2012, 9, 245-252.

(C) 2013 by the authors; licensee MDPI, Basel, Switzerland. This article is an open access article distributed under the terms and conditions of the Creative Commons Attribution license (http://creativecommons.org/licenses/by/3.0/). 